Journal of Neurology, Neurosurgery and Psychiatry - Guest Speaker

\title{
006 STRESS AND WAR: THE LIMITS OF NEUROPSYCHIATRY
}

doi:10.1136/jnnp-2013-306103.6

Neil Greenberg

Professor Neil Greenberg is an academic psychiatrist based at King's College London UK and is a consultant occupational and forensic psychiatrist. Neil served in the United Kingdom Armed Forces for more than 23 years and has deployed, as a psychiatrist and researcher, to a number of hostile environments including Afghanistan and Iraq.

Neil studied medicine at Southampton University and graduated in 1993. He then served as a general duties doctor in a variety of Warships, Submarines and with two Royal Marines 
Commando units. During his time with the Royal Marines he achieved his arctic warfare qualification and completed the all arms commando course, earning the coveted Green Beret.

Neil has specialised in Psychiatry and completed a Masters Degree in Clinical Psychiatry, a Doctorate in Mental Health and is a Fellow of the Royal College of Psychiatrists. He is a specialist in General Adult, Forensic and Liaison Psychiatry and is a member of the faculty of forensic and legal medicine and the faculty of medical leadership and management. Since 1997 Neil has been at the forefront of developing peer led traumatic stress support packages which is now in use by a wide variety of organisations. The use of Trauma Risk Management (TRiM) was initially led by the Royal Marines and has since been taken up by other organisations including the Foreign and Commonwealth Office, media organisations numerous UK police forces and the London Ambulance Service.

Neil provided psychological input for Foreign Office personnel after the events of September 11th 2001 and in Bali after 12th October 2002 bombings. He has also assisted with the aftermath management of number of other significant incidents including assisting the London Ambulance Service in the wake of the London Bombings in 2005. He has also provided mental health input into the psychological repatriation of a number of hostages over the past five years. In 2008 he was awarded the Gilbert Blane Medal by the Royal Navy for his work in supporting the health of Naval personnel through his research work.

Neil has published more than 120 scientific papers, book chapters and has presented to national and international audiences on matters concerning the psychological health of the UK Armed Forces, organisational management of traumatic stress and occupational mental health. He has been the secretary of the European Society for Traumatic Stress Studies, is a current executive board member of the UK Psychological Trauma Society and is an examiner on the Diploma in the Medical Care of Catastrophes.

Neil has extensive experiences of conducting research in military and veteran populations and has successfully published the first two ever randomised controlled trials on the effectiveness of psychological health interventions in the UK Armed Forces. He has established excellent links with veteran health providers and with US and other coalition military mental health providers and researchers. He, along with the team at King's College London, is one of the UK's premier military health researchers and has published very widely on a broad spectrum of military health related topics (www.kcl.ac.uk/kcmhr) and advise both the Armed Forces and UK governments regularly about mental health issues.

Neil has worked with News International and other media organisations including the BBC for about ten years and has provided expert input to emerging crises and clinical assessments.

The mental health of the United Kingdom Armed Forces is a 'hot topic'. It is rare that a week goes by without a high profile media article or a senior politician commenting on the topic. However, whilst the research efforts which have investigated the psychological wellbeing of the UK Armed Forces are considerable, the results of these studies are not always well understood. Whilst there can be little doubt that for some individuals deployment to an operational theatre can be highly challenging, the emergence of new mental health problems remains uncommon. The aim of this lecture is to provide an evidence based overview of the health of the UK Armed Forces exploring how personnel's mental health varies depending on the stage of deployment (before, during and after) and the health of reservists and veterans in order to both identify the emerging issues and also to dispel some of the common myths. Much of the presented material originates from the King's Centre for Military Health Research and the Academic Centre for Defence Mental Health both based at King's College London which is the UK's leading military mental health research establishment led by Professor Sir Simon Wessely. 